\title{
PROJETO E IMPLANTAÇÃO DE UM CURSO DE OPERADOR DE USINAS TERMELÉTRICAS ARTICULADO COM EMPRESAS DO COMPLEXO INDUSTRIAL E PORTUÁRIO DO PECÉM
}

Marcel Ribeiro Mendonça-marcel.ribeiro@ifce.edu.br

Instituto Federal do Ceará - campus Avançado Pecém

Rodovia CE-422, km 04, Complexo Industrial e Portuário do Pecém

CEP 61642-000 - Caucaia - CE

Marcilia Maria Soares Barbosa Macedo-marcilia@ifce.edu.br

Instituto Federal do Ceará - campus Caucaia

Rua Francisco da Rocha Martins, S/N, Pabussu

CEP 61609-090 - Caucaia - CE

Resumo: Este trabalho apresenta uma sintese da metodologia adotada para planejamento e execução de um curso de formação de Operadores de Usinas Termelétricas. No trabalho, é descrito o percurso metodológico para elaboração do projeto pedagógico do curso, bem como de sua matriz curricular, ambos desenvolvidos com a participação direta de empresas administradoras de usinas termelétricas instaladas na região do Complexo Industrial e Portuário do Pecém. Também são apresentados aspectos práticos sobre a execução do curso, como foi a participação dos profissionais das empresas envolvidas durante o desenvolvimento do projeto, por meio de atividades curriculares, palestras e visitas técnicas. Por fim, são avaliados e comparados alguns indicadores de permanência e êxito dos ingressantes no curso, bem como são apresentados os dados de empregabilidade dos concludentes, com ênfase nas empresas do segmento em estudo.

Palavras-chave: Usinas Termelétricas. Qualificação Profissional. Extensão. 


\section{INTRODUÇÃO}

O Complexo Industrial e Portuário do Pecém (CIPP), na atualidade, constitui-se como um dos grandes vetores de desenvolvimento dos segmentos industrial e de logística do Estado do Ceará. Além do Porto do Pecém, o complexo conta com industrias de segmentos como de movimentação de cargas, geração de energia elétrica, fabricação de cimento, pás para turbinas eólicas, louças cerâmicas, tubulações de aço, entre outras. Além disso, possui a única siderúrgica integrada em operação nas regiões norte-nordeste do Brasil, e a única Zona de Processamento de Exportação (ZPE) em funcionamento e com indústrias no país. O complexo ocupa uma área total de 13.337 hectares entre os municípios de Caucaia e de São Gonçalo do Amarante, na região metropolitana de Fortaleza, e no total, já recebeu investimentos da ordem de $\mathrm{R} \$ 28,3$ bilhões (AECIPP, 2020).

Atualmente, estima-se que cerca de 61 mil empregos diretos e indiretos sejam gerados pelas empresas do CIPP. Contudo, a pouca qualificação da mão de obra local tradicionalmente se apresenta como um dos entraves para o crescimento do setor industrial (CHIARA e GAVRAS, 2019) (GERBELLI, 2020). É comum que empresas, por livre iniciativa, fomentem o surgimento de programas de qualificação profissional, em especial aqueles que utilizam, para isso, o instituto da Lei de Aprendizagem.

A ausência de mão de obra qualificada afeta não somente os níveis de operação e manutenção, mas também os níveis de coordenação, gerência e alta gestão. Com isso, frequentemente observa-se que as empresas do CIPP fazem a captação de mão de obra em outros estados do país.

Desta forma, este trabalho irá descrever uma proposta de metodologia de planejamento e execução, adotada para a concepção de um curso de formação de Operadores de Usinas Termelétricas, que qualificou profissionais com formação técnica de nível médio, ou superior em Engenharia, mas sem experiência no setor. Com isso, espera-se que as empresas priorizem a contratação de profissionais oriundos do curso introduzindo, desta forma, a mão de obra local em funções onde até então esta não estava inserida.

\section{JUSTIFICATIVA}

A instalação de novos empreendimentos industriais, frequentemente gera, nas comunidades residentes no entorno destes empreendimentos, uma expectativa de contratação e aproveitamento da mão de obra local. Nos últimos 20 anos, diversos empreendimentos foram implantados no CIPP. No entanto, o nível de especificidade de algumas profissões, em especial as dos setores siderúrgico e de geração termelétrica, frustraram parcialmente a população, que ficou muitas vezes limitada a ocupar atividades de baixa complexidade, de demanda sazonal, e consequentemente, com menores salários. Esta situação tende a suscitar conflitos e litígios, que demandam a mediação, ou mesmo a intervenção, das diversas esferas do poder público (ASSEMBLEIA, 2017).

O segmento de geração de energia elétrica tem especial relevância na economia do CIPP. Segundo o Operador Nacional do Sistema (ONS, 2020), o complexo atualmente possui cinco usinas de geração termelétrica, listadas na Tabela 1. Juntas, estas empresas correspondem a uma potência instalada de $1,853 \mathrm{GW}$, com estimativa de que cerca de 5 mil empregos diretos e indiretos tenham sido gerados desde sua implantação. Estas usinas utilizam gás (natural ou oriundo de resíduos industriais) ou carvão como combustível. Além delas, o complexo também possui duas fábricas de pás para turbinas eólicas, e tem instalado em suas proximidades um complexo de geração de energia eólica. 
Tabela 1 - Empreendimentos de geração termelétrica ativos no CIPP

\begin{tabular}{|c|c|c|}
\hline Agente & Combustível & Potência Instalada \\
\hline Porto Pecém Geração de Energia S/A (EDP) & Carvão & $720 \mathrm{MW}$ \\
\hline Pecém II Geração de Energia S/A (ENEVA) & Carvão & $365 \mathrm{MW}$ \\
\hline CSP - Companhia Siderúrgica do Pecém & Resíduos Industriais & $218 \mathrm{MW}$ \\
\hline Central Geradora Termelétrica Fortaleza S/A & Gás & $327 \mathrm{MW}$ \\
\hline Petróleo Brasileiro S/A & Gás & $223 \mathrm{MW}$ \\
\hline TOTAL & & $\mathbf{1 . 8 5 3} \mathbf{M W}$ \\
\hline
\end{tabular}

Fonte: ONS (2020)

Para atuar no setor, é comum que estas empresas exijam formação mínima em nível técnico, para os setores de operação e manutenção. Para os setores de coordenação, supervisão, análise e gestão, frequentemente é exigida a formação em Engenharia. Grande parte das instituições de ensino, de ambos os níveis, não proporciona formação que atenda às necessidades do setor, já que frequentemente é exigido dos profissionais uma formação multidisciplinar com foco em geração termelétrica, que envolve áreas como combustíveis, combustão, termodinâmica, sistemas elétricos, tratamento de água, meio ambiente, automação, instrumentação, entre outros.

De acordo com o Catálogo Brasileiro de Ocupações (CBO), o Operador de Usina Termelétrica é o um profissional que opera instalações de sistemas elétricos, mecânicos, hidráulicos e de instrumentação, e controla grandezas eletromecânicas inerentes ao processo. Também é responsável por manobrar equipamentos de manutenção, inspecionar equipamentos, elaborar relatórios técnicos, e seguir normas e procedimentos ocupacionais de saúde e segurança. Para atuar no segmento, também se recomenda frequentar curso de qualificação com em torno de 400 horas aula.

\section{METODOLOGIA}

As instituições de Educação Profissional e Tecnológica (EPT), nos últimos anos, tem desenvolvido organizações curriculares cada vez mais alinhadas ao setor produtivo. $\mathrm{O}$ currículo, neste contexto, acaba por se configurar como o produto das diversas atividades de aprendizagem e experiências vivenciadas pelo estudante, inclusive por meio de atividades não formais. Esta modernização tem se fundamentado, principalmente, nos conceitos de formação por competências, na possibilidade de flexibilização do currículo, e por fim, nas próprias características e finalidades da EPT (BARBOSA et al, 2001).

A metodologia adotada para o planejamento e execução do curso tomou como premissa a necessidade de diálogo constante entre as instituições. Em projetos desta natureza, é importante que os conhecimentos e habilidades de cada componente das equipes seja potencializado nas ações propostas. Além disso, é importante destacar que frequentemente são observados elevados indicadores de evasão e retenção em muitos cursos desta natureza, e de que a metodologia proposta deverá buscar a redução deste indicadores, seja por meio de um processo seletivo mais criterioso em relação à formação prévia do estudante, ou mesmo por meio de ações motivadoras ao longo da execução do curso.

A Figura 1 resume a proposta de metodologia adotada para execução do projeto. A metodologia prevê a existência de uma etapa de concepção e fundamentação, realizada continuamente pelo campus e de forma anterior ao planejamento prévio do curso; a etapa de planejamento, mais diretamente ligada ao projeto do curso proposto; e a etapa de execução 
propriamente dita, composta pelo processo seletivo, realização do curso, e processo seletivo posterior de concludentes.

Figura 1 - Proposta de metodologia adotada para execução do projeto

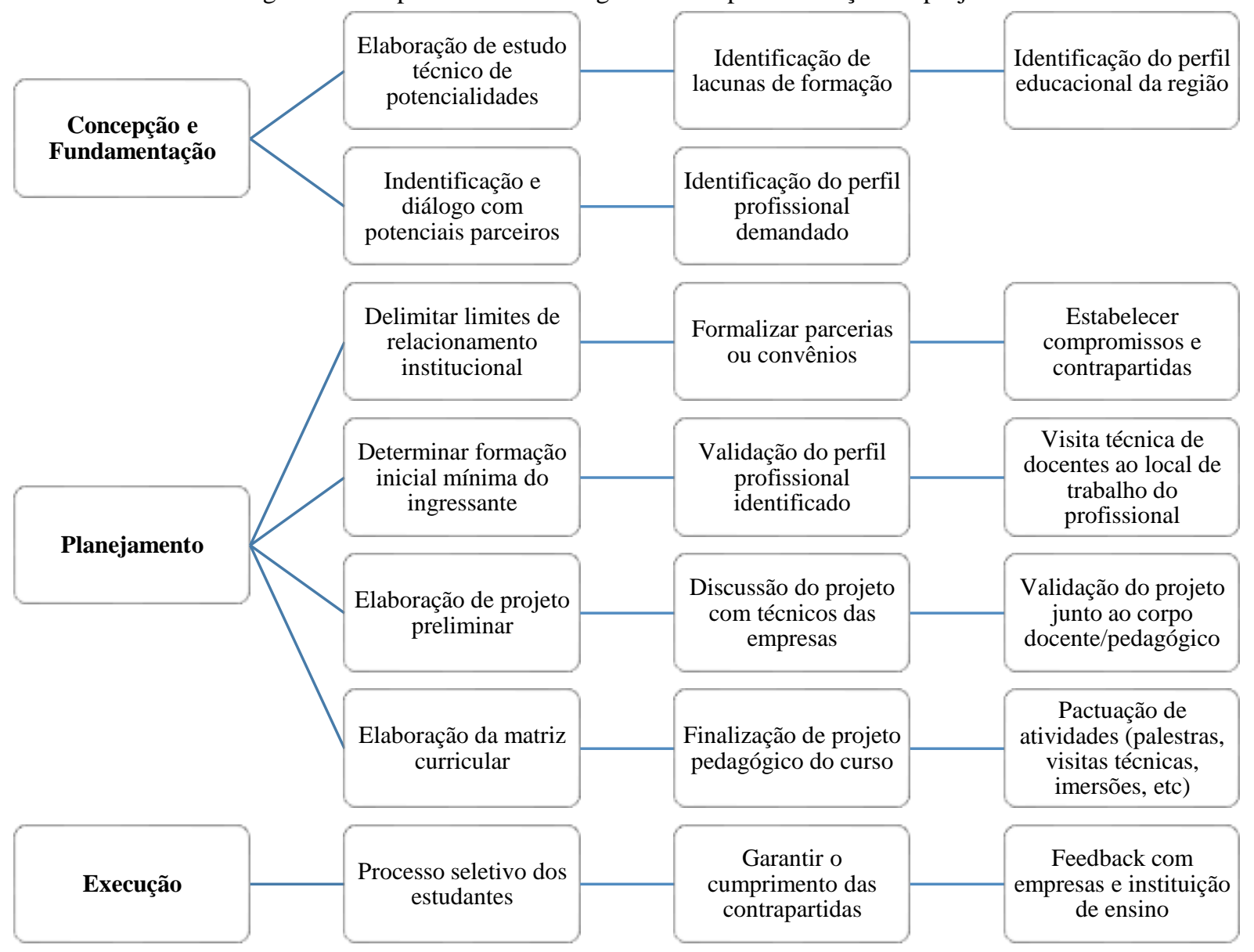

Fonte: Elaborado pelo autor

\subsection{Concepção e fundamentação}

Desde a implantação do IFCE campus avançado Pecém, ações de caracterização e identificação de potencialidades regionais têm sido desenvolvidas, com o intuito de direcionar esforços às reais necessidades da comunidade. Por este motivo, desde 2017, a instituição formulou um estudo de potencialidades para implantação de novos cursos, que analisa as potencialidades socioeconômicas, o mercado de trabalho, o perfil educacional da região e as demandas por qualificação dos residentes e das empresas instaladas (IFCE, 2017).

Por meio do estudo, foi possível identificar setores com a ausência de profissionais qualificados em determinadas ocupações, o perfil de educação formal da população, e o perfil de oferta de educação técnica e superior na região. Além disso, a elaboração do estudo possibilitou um diálogo inicial com potenciais parceiros. Neste contexto, foi identificado que o setor de geração de energia termelétrica possuía uma demanda recorrente por operadores de usinas termelétricas, que devido à inexistência de formação na região, buscava profissionais formados em outros estados do país.

\subsection{Planejamento}

Durante o planejamento do curso, foi importante pactuar os limites de relacionamento institucional entre os parceiros. Nesta etapa é necessário buscar denominadores comuns entre 
os interesses de cada instituição. No caso deste curso, já existia um convênio formalizado entre as empresas e uma associação representativa destas empresas. Assim, delimitou-se que o interesse das instituições era de realizar uma oferta pública e gratuita do curso de formação, exclusivo para pessoas já qualificadas em nível técnico ou superior em engenharia, preferencialmente residentes nas proximidades do CIPP. Além disso, estabeleceu-se que as empresas parceiras realizariam processos seletivos com os concludentes do curso, para desenvolvimento de estágios supervisionados, ou para contratação dos concludentes para período de experiência.

Posteriormente, foi feita a validação do perfil esperado do egresso, por meio de reuniões com gestores das áreas de recursos humanos, operação e manutenção, e docentes das áreas de química, elétrica, mecânica, qualidade e segurança do IFCE. Além disso, foram identificados os requisitos, competências e habilidades esperadas para os profissionais que seriam formados pelo curso.

Nesta etapa, além das reuniões entre as equipes de gestão, os docentes realizaram uma imersão, durante um dia, nos diversos processos das empresas participantes. Na imersão, foi possível identificar particularidades de como seria a atuação destes profissionais nas usinas, em cada um de seus subprocessos. Posteriormente, os docentes propuseram uma matriz curricular, bem como seus conteúdos programáticos, que foram posteriormente validados em reunião conjunta com os gestores das empresas. Por fim, também foi delimitado o perfil mínimo de formação exigido para os estudantes.

A etapa de planejamento, iniciada na primeira reunião realizada entre as equipes do projeto, e concluída após a abertura oferta pública do curso, durou cerca de três meses.

\subsection{Execução}

A garantia do perfil de formação mínimo é imprescindível nesta etapa por dois fatores: em primeiro lugar, como o curso ofertado será de curta duração, não há tempo para proporcionar formação em conteúdos básicos ao estudante, portanto, espera-se que o mesmo já detenha algum conhecimento em áreas correlatas ao curso; E em segundo lugar, é necessário adequar a formação mínima solicitada para ingresso no curso à formação mínima solicitada para ingresso nas empresas. Caso este alinhamento não ocorra já no processo seletivo, mesmo que o estudante seja aprovado e conclua o curso, ele não poderá ingressar na empresa, já que muitas vezes estas possuem regramentos próprios de seleção e provimento em vagas exigindo-se, por exemplo, a formação em nível técnico ou superior do estudante.

Também é importante garantir o cumprimento das contrapartidas pactuadas entre ambas as instituições. Desta forma, é fundamental que as empresas cumpram com os cronogramas das atividades pactuadas, em especial nas palestras e visitas técnicas, que darão ao estudante uma visão prática dos conteúdos ministrados. E, ao mesmo tempo, que o corpo docente desenvolva seu planejamento de atividades alinhado ao pactuado nos projetos pedagógicos. Este acompanhamento pode ser potencializado por meio das reuniões dos conselhos de classe, onde eventuais dificuldades do corpo docente poderão ser socializadas ao longo da execução do curso.

\section{RESULTADOS}

Após as etapas de planejamento, a matriz curricular e o conteúdo programático do curso foram propostos e validados junto às empresas e à instituição de ensino. A matriz curricular proporciona, desta forma, o contato com um conjunto de conteúdos e experiências que farão com que o estudante possa iniciar suas atividades nas empresas de forma mais assertiva. 
A proposta de trabalho adotada foi a de oferta de um curso com carga horária total de 400 horas, ministrado de segunda-feira a sexta-feira das 13:30 às 17:45 por um período de cinco meses, iniciados a partir de agosto de 2019. Do total, 344 horas foram ministradas por docentes do IFCE, e 56 horas por técnicos das empresas, que desenvolveram estas horas de aula por meio de palestras sobre a aplicação daquela disciplina à vivência do profissional, e visitas técnicas às empresas no primeiro, terceiro e no quinto mês de aulas.

A Tabela 2 apresenta um resumo das disciplinas pactuadas, bem como a distribuição de cargas horárias e atividades que seriam desenvolvidas pelo IFCE e pelas empresas parceiras. Para cada uma das disciplinas, foi estabelecida uma carga horária a ser desenvolvida por alguma das empresas do setor, e o formato desta atividade.

Tabela 2 - Matriz curricular do curso proposto

\begin{tabular}{|c|c|c|c|c|c|}
\hline $\begin{array}{l}\text { Nome do } \\
\text { Módulo/ } \\
\text { disciplina }\end{array}$ & Ementa resumida & 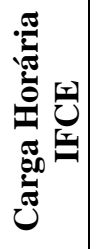 & 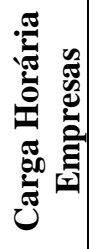 & 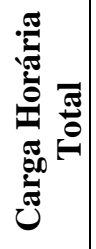 & Atividade \\
\hline $\begin{array}{l}\text { Tratamento de } \\
\text { Água }\end{array}$ & $\begin{array}{l}\text { Qualidade da água, tecnologias de tratamento de água, } \\
\text { desmineralização, geração de vapor em caldeiras, torres de } \\
\text { resfriamento, tratamento químico de caldeiras e torres }\end{array}$ & 36 & 4 & 40 & 1 palestra \\
\hline $\begin{array}{l}\text { Combustíveis e } \\
\text { Combustão }\end{array}$ & $\begin{array}{l}\text { Principais combustíveis em termelétricas, queimadores, } \\
\text { processos de combustão, reações químicas associadas ao } \\
\text { processo de combustão, poluentes atmosféricos. }\end{array}$ & 32 & 8 & 40 & 2 palestras \\
\hline $\begin{array}{l}\text { Termodinâmica } \\
\text { e Transmissão } \\
\text { de Calor }\end{array}$ & $\begin{array}{l}\text { Leis da termodinâmica, transferência de calor (condução, } \\
\text { convecção, radiação), aplicações de transferência de calor }\end{array}$ & 36 & 4 & 40 & 1 palestra \\
\hline $\begin{array}{l}\text { Controle de } \\
\text { Processos } \\
\text { Industriais } \\
\end{array}$ & $\begin{array}{l}\text { Sistemas de controle em processos de geração, nível de } \\
\text { alimentação, condensadores, tambores e temperatura }\end{array}$ & 64 & 16 & 80 & 4 palestras \\
\hline $\begin{array}{l}\text { Máquinas e } \\
\text { Equipamentos }\end{array}$ & $\begin{array}{c}\text { Princípios de máquinas de fluxo, curvas características, } \\
\text { equações fundamentais, bombas, sistemas de } \\
\text { bombeamento, ventiladores, turbinas hidráulicas }\end{array}$ & 56 & 4 & 60 & $\begin{array}{l}1 \text { visita } \\
\text { técnica }\end{array}$ \\
\hline $\begin{array}{l}\text { Automação } \\
\text { Industrial }\end{array}$ & $\begin{array}{c}\text { Sensores e atuadores industriais, controladores lógicos } \\
\text { programáveis, sistemas de controle e supervisão, aplicações } \\
\text { de automação em geração termelétrica }\end{array}$ & 32 & 8 & 40 & 2 palestras \\
\hline $\begin{array}{c}\text { Geração } \\
\text { Termelétrica }\end{array}$ & $\begin{array}{l}\text { Geração termelétrica a gás natural e carvão, equipamentos e } \\
\text { etapas, tipos de turbinas e geradores, subestações }\end{array}$ & 36 & 4 & 40 & $\begin{array}{l}1 \text { visita } \\
\text { técnica }\end{array}$ \\
\hline $\begin{array}{l}\text { Controle } \\
\text { Ambiental }\end{array}$ & $\begin{array}{l}\text { Aspectos legais, emissões atmosférias, efluentes e resíduos, } \\
\text { geração, tratamento e disposição de resíduos sólidos }\end{array}$ & 16 & 4 & 20 & 1 palestra \\
\hline $\begin{array}{l}\text { Sistemas } \\
\text { Elétricos }\end{array}$ & $\begin{array}{l}\text { Organização do sistema elétrico brasileiro, sistema } \\
\text { interligado nacional, sistemas elétricos de potência } \\
\text { (geração, transmissão e distribuição) }\end{array}$ & 36 & 4 & 40 & $\begin{array}{l}1 \text { visita } \\
\text { técnica }\end{array}$ \\
\hline \multicolumn{2}{|c|}{ TOTAL } & 344 & 56 & 400 & $\begin{array}{c}14 \\
\text { atividades }\end{array}$ \\
\hline
\end{tabular}

Fonte: Elaborado pelo autor

Em cada componente curricular foi desenvolvido, no mínimo, uma palestra técnica, ministrada por profissionais que atuem no setor da empresa correspondente à disciplina, como forma de apresentar uma perspectiva de aplicação prática da disciplina. Nas visitas técnicas, os estudantes faziam uma imersão em setores específicos. Estas, normalmente aconteciam no mesmo dia em que uma das palestras, de tal maneira que os estudantes permaneciam durante todo o dia na empresa. 
A etapa de seleção do curso contou com pouco mais de 200 inscritos. Para participação no processo seletivo, foi estabelecido como requisito mínimo de escolaridade o ensino médio completo, e curso de formação técnica ou superior nas áreas de eletrotécnica, eletromecânica, automação industrial, eletroeletrônica, metalurgia, química, petroquímica ou áreas afins (em andamento ou concluído).

A Figura 2 apresenta um comparativo entre o percentual de estudantes concludentes, evadidos e em fluxo, em três tipos de amostras: na primeira, é apresentada somente a situação final dos 30 estudantes do curso de Operador de Usinas Termelétricas. Já a segunda e a terceira apresentam a situação final nos cursos de qualificação profissional no IFCE campus Avançado Pecém, e em todos os cursos de qualificação profissional do IFCE, respectivamente com um total de 687 e 8.507 estudantes, segundo dados da Plataforma Nilo Peçanha 2020 (ano base 2019).

Pela análise dos gráficos, é possível constatar que, enquanto a média de concludentes no campus e no IFCE é de respectivamente $54,1 \%$ e 59,9\%, a média de concludentes no curso de Operador de Usinas Termelétricas foi de 83,3\%. Além disso, o curso teve $10 \%$ de seus estudantes evadidos, número bastante inferior ao observado na média dos cursos de qualificação profissional do campus, que estava em $43,7 \%$.

Figura 2 - Comparação entre o percentual de estudantes concludentes, evadidos e em fluxo

\section{Comparativo da situação final de estudantes em três tipos de curso}

$$
\begin{array}{lllllllllll}
0 \% & 10 \% & 20 \% & 30 \% & 40 \% & 50 \% & 60 \% & 70 \% & 80 \% & 90 \% & 100 \%
\end{array}
$$

Operador de Usinas Termelétricas

Q.P. no IFCE Pecém/2019

Q.P. no IFCE/2019

\begin{tabular}{|c|c|c|c|c|}
\hline & $83,3 \%$ & \multicolumn{2}{|r|}{$6,7 \%$} & \multicolumn{2}{|c|}{$10 \%$} \\
\hline & $54,1 \%$ & $2,2 \%$ & $43,7 \%$ & \\
\hline & & & & \\
\hline & $59,9 \%$ & & $33,5 \%$ & $6,5 \%$ \\
\hline
\end{tabular}

Concludentes Em fluxo (cursando ou retidos) $\square$ Evadidos

Fonte: Elaborado pelo Autor

Durante a execução do curso, foi possível observar que os estudantes se mantiveram bastante motivados, em especial devido à real possibilidade de ingresso na carreira em uma das empresas do CIPP. Além disso, por ser uma oferta praticamente única na região nordeste, muitos também tinham a expectativa de receber oportunidades de emprego em outras localidades do país. Logo no encerramento do curso, 12 estudantes foram contratados por empresas, e os demais foram cadastrados para oportunidades futuras. Também foi possível observar que os três estudantes que evadiram ao longo do curso, o fizeram por incompatibilidade no horário das aulas e do trabalho.

\section{CONSIDERAÇÕES FINAIS}

A busca por propostas curriculares cada vez mais alinhadas às demandas latentes do setor produtivo tem se constituído como um dos grandes desafios dos sistemas educacionais, e em especial nas instituições especializadas na oferta de curso de Educação Profissional e Tecnológica. Como foi possível observar, o curso apresentou índices de permanência e êxito bastante superiores à media dos cursos oferecidos quando comparado aos cursos ofertados no campus e em todos os demais campi do IFCE. 
A metodologia apresentada neste trabalho pode auxiliar no desenvolvimento de propostas curriculares mais assertivas em relação a estas demandas, e mais atrativas ao corpo discente, contribuindo com a melhoria dos indicadores de permanência e êxito não somente neste tipo de curso, mas também em cursos de nível técnico, e em especial na educação superior. Contudo, apesar de a metodologia ter apresentado números positivos nos indicadores de permanência e êxito estudantil, ainda observou-se que um pequeno número de estudantes não conseguiu concluir o curso. Esta situação ocorreu tanto devido à reprovação em um ou mais módulos de disciplinas (no caso de estudantes retidos), quanto por desistência voluntária ocorrida por motivos de horários de trabalho incompatíveis com o horário do curso.

Também é importante destacar que este tipo de trabalho integrado entre empresas e instituição de ensino, pode induzir a criação de outros tipos de ações, como programas de estágio, projetos de pesquisa e extensão, prestação de serviços tecnológicos, entre outros. Sabese que este tipo de ação também acaba melhorando, ainda que indiretamente, os indicadores de permanência e êxito em todos os cursos da unidade. Assim, a criação de canais de diálogo permanente com empresas e suas instituições representativas, observando-se os limites de atuação institucional, a autonomia administrativa e pedagógica das instituições de ensino, e os princípios da administração pública, podem contribuir para que a instituição potencialize suas ofertas formativas, bem como a formação de capital humano.

Como proposta de trabalhos futuros, sugere-se a criação de mecanismos que possibilitem um controle mais adequado de estudantes que potencialmente possam converter-se em evasão ao longo do curso. Além disso, a abertura de diálogo entre a instituição de ensino e as empresas poderão possibilitar que eventuais desistências do curso em virtude de incompatibilidade de horários de trabalho sejam revertidas.

\section{REFERÊNCIAS}

AECIPP. CIPP - A nova ordem industrial e logística do Ceará. Disponível em: http://www.aecipp.com.br/pt-br/cipp. Acesso em: 14 jul. 2020.

ASSEMBLEIA Legislativa do Ceará. Qualificação e mais vagas para cearenses no Pecém são cobradas em audiência. Portal de Notícias da Assembleia Legislativa do Ceará, Fortaleza, 10 abr 2017. Últimas Notícias. Disponível em: https://www.al.ce.gov.br/index.php/ultimasnoticias/item/62999-10-04-2017-1f01. Acesso em: 10 jun 2020.

BARBOSA, Eduardo Fernandes; MARTINS, Rachel Cruz; ROCHA, Marli Ferreira. O planejamento curricular para a Educação Profissional no modelo de competências. Educação \& Tecnologia, Belo Horizonte, v.6, n.1/2, p.49-59, 2001

CEARÁ. Assembleia Legislativa. Cenário atual do complexo industrial e portuário do Pecém / Conselho de Altos Estudos e Assuntos Estratégicos, Assembleia Legislativa do Estado do Ceará; Eudoro Walter de Santana (Coordenador). - Fortaleza-CE: INESP, 2013.

CHIARA, Márcia de; GAVRAS, Douglas. Sem qualificação, parte dos brasileiros não consegue ocupar vagas básicas. O Estado de São Paulo. São Paulo-SP: 02 jun 2019. Disponível em: https://economia.estadao.com.br/noticias/geral,sem-qualificacao-parte-dos-brasileiros-naoconsegue-ocupar-vagas-basicas,70002852842. Acesso em: 10 jul 2020.

GERBELLI, Luiz Guilherme. Falta de mão de obra qualificada afeta metade das indústrias do país. G1. Caderno Economia. São Paulo-SP: 11 fev 2020. Disponível em: 
https://g1.globo.com/economia/concursos-e-emprego/noticia/2020/02/11/falta-de-mao-deobra-qualificada-afeta-metade-das-industrias-do-pais.ghtml. Acesso em: 10 jul 2020

IFCE. Estudo de Potencialidades para implantação de novos cursos no IFCE Campus Avançado Pecém. Caucaia-CE: Abril 2017. Disponível em: https://ifce.edu.br/pecem/campuspecem/documentos-e-editais-do-campus/documentos-institucionais/estudo-depotencialidades-06-06-2018.pdf/view. Acesso em: 10 jul 2020.

ONS. Mapa Dinâmico do SIN. Disponível em: http://www.ons.org.br/paginas/sobre-osin/mapas. Acesso em: 15 jul 2020 


\title{
DESIGN AND IMPLEMENTATION OF A TRAINING COURSE FOR THERMAL POWER PLANTS OPERATORS IN ASSOCIATION WITH COMPANIES OF PECÉM INDUSTRIAL AND PORT COMPLEX
}

\begin{abstract}
This paper presents an overview of the methodology adopted for planning and execution of an operators for Thermal Power Plants training course. In the paper, the methodologies to formulate the pedagogical project and the curriculum of the course are described. The course was developed in association with companies that manage thermoelectric plants installed in Pecém Industrial and Port Complex. Practical aspects of the course execution will also be presented, such as the participation of professionals from the companies involved during the course's development, through curricular activities, lectures and technical visits. Finally, the course completion rates of the graduates of this course will be evaluated, when compared to the graduates of the other courses, as well as the employability data of the graduates, with emphasis on companies in the segment under study.
\end{abstract}

Keywords: Thermoelectric power plants. Continuing Education. Extension. 